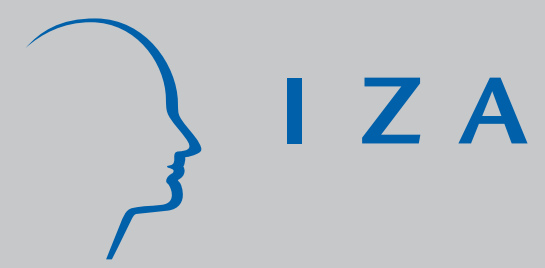

IZA DP No. 8673

Labor Market Effects of Intrauterine Exposure to Nutritional Deficiency: Evidence from Administrative Data on Muslim Immigrants in Denmark

Marie Louise Schultz-Nielsen

Erdal Tekin

Jane Greve

November 2014 


\title{
Labor Market Effects of Intrauterine Exposure to Nutritional Deficiency: Evidence from Administrative Data on Muslim Immigrants in Denmark
}

\author{
Marie Louise Schultz-Nielsen \\ Rockwool Foundation Research Unit and IZA \\ Erdal Tekin \\ American University, IZA and NBER \\ Jane Greve \\ Rockwool Foundation Research Unit \\ Discussion Paper No. 8673 \\ November 2014 \\ IZA \\ P.O. Box 7240 \\ 53072 Bonn \\ Germany \\ Phone: +49-228-3894-0 \\ Fax: +49-228-3894-180 \\ E-mail: iza@iza.org
}

\begin{abstract}
Any opinions expressed here are those of the author(s) and not those of IZA. Research published in this series may include views on policy, but the institute itself takes no institutional policy positions. The IZA research network is committed to the IZA Guiding Principles of Research Integrity.

The Institute for the Study of Labor (IZA) in Bonn is a local and virtual international research center and a place of communication between science, politics and business. IZA is an independent nonprofit organization supported by Deutsche Post Foundation. The center is associated with the University of Bonn and offers a stimulating research environment through its international network, workshops and conferences, data service, project support, research visits and doctoral program. IZA engages in (i) original and internationally competitive research in all fields of labor economics, (ii) development of policy concepts, and (iii) dissemination of research results and concepts to the interested public.
\end{abstract}

IZA Discussion Papers often represent preliminary work and are circulated to encourage discussion. Citation of such a paper should account for its provisional character. A revised version may be available directly from the author. 
IZA Discussion Paper No. 8673

November 2014

\section{ABSTRACT \\ Labor Market Effects of Intrauterine Exposure to Nutritional Deficiency: Evidence from Administrative Data on Muslim Immigrants in Denmark ${ }^{*}$}

This paper examines whether nutritional disruptions experienced during the stage of fetal development impair an individual's labor market productivity later in life. We consider intrauterine exposure to the month of Ramadan as a natural experiment that might cause shocks to the inflow of nutrients essential for fetal development. Specifically, we use administrative data from Denmark to investigate the impact of exposure to Ramadan in utero on labor market outcomes of adult Muslim males, including employment status, annual salary, hourly wage rate, and hours of work. Our findings indicate that potential exposure to nutritional disruptions during a critical stage of fetal development has scarring effects on the fetus expressed as poor labor market outcomes later in life. Specifically, exposure to Ramadan in the $7^{\text {th }}$ month of gestation results in a lower likelihood of employment, a lower salary, and reduced labor supply, but not necessarily a lower wage rate. We also document suggestive evidence that these results may partially be driven by increased disability and to a lesser extent by poor educational attainment among those who were exposed to Ramadan during this particular period in utero.

JEL Classification: I1, I12, J1, J13, J22, J24, J3

Keywords: Ramadan, fetal origins, Intrauterine, Denmark, nutrition, wage, labor, Muslim

Corresponding author:

Erdal Tekin

School of Public Affairs

American University

4400 Massachusetts Avenue NW

Washington, DC 20016-8070

USA

E-mail: tekin@american.edu

\footnotetext{
* This research is supported by a grant (12-125309) from the Danish Council for Independent Research. We thank Janet Currie, Ezra Susser, Daniel Rees, and the seminar participants at the Rockwool Foundation for comments and suggestions offered. The authors are solely responsible for any views expressed.
} 


\section{Introduction}

The impact of intrauterine conditions on the well-being of infants at birth and during adulthood has been a focus of major interest in epidemiology since the pioneering study of Stein et al. (1975) on the long-term health consequences of prenatal famine exposure. The proposition that fetal malnutrition could have long-term implications for an individual's health gained a new impulse in the 1990s following a series of studies by David Barker, who argued that many adult chronic diseases have origins in utero (Barker, 1990; 1995; 2002). This argument, which has become known as the "fetal origins hypothesis," posits that adaptations to nutritional insufficiency during the intrauterine growth period may permanently alter the physiology and metabolism of the fetus through a process called fetal reprogramming, which, in turn, may increase the risk of disease in adulthood (Barker, 2002; Godfrey and Barker, 2000, 2001). The implications of the fetal origins hypothesis for health outcomes have been extensively studied in the epidemiological literature (e.g., Susser et al., 1996; Susser and Lin, 1992; Heijmans et al., 2008; Lumey, Stein, and Susser, 2011; Susser and Clair, 2013).

More recently, the fetal origins hypothesis has also attracted the attention of economists. Motivated by the growing evidence establishing a causal relationship between initial endowments and early life investments and future health and human capital accumulation (e.g., Heckman, 2007; Doyle et al., 2009), research by economists has typically considered outcomes such as birthweight, health, test scores and educational attainment, labor market performance, and mortality (Almond, 2006; Almond and Mazumder, 2011; Almond, Mazumder, van Ewijk, 2011; Majid, 2013; van Ewijk, 201l, Mansour and Rees, 2012; Neelsen and Stratmann, 2011; Hernandez-Julian, Mansour, and Peters, in press; Scholte, Van den Berg, and Lindeboom, 
2012). ${ }^{1}$ One common thread through much of this research is the use of extreme real life events such as famines, war, and pandemics as the primary sources of variation for identification. ${ }^{2}$ One advantage of this approach is that these events typically have well-defined start and end dates. Therefore, the birth cohorts exposed to these extreme events can be identified with relative certainty. But more importantly, these events are considered natural experiments, i.e., they are uncorrelated with other determinants of health, such as income, maternal education, or prenatal care. Therefore, the evidence obtained from these studies has a causal interpretation (Almond and Currie, 2011). However, the disadvantage of using extreme natural events is that they are relatively rare occurrences, especially in the context of societies in developed countries. Therefore, the generalizability of conclusions drawn from these events to milder, but more commonly experienced intrauterine shocks, such as undernourishment and disruptions to nutrients, is complicated (Almond and Currie, 2011). Since extreme natural events are not typically preventable by individual behaviors, evidence from these studies also provides little scope for public policies aimed at inducing behaviors that would mitigate the adverse consequences of extreme natural events (Almond, Mazumder, and van Ewijk, 2011). Additionally, most of the evidence on these extreme natural events either come from less developed countries (e.g., the Bangladeshi famine of 1974, the Chinese famine of 1959-61) or from western societies exposed to these shocks in the distant past (e.g., the Dutch famine of 1944-45, the 1957 avian flu pandemic in Britain, the 1918 influenza pandemic in the United States, the Greek famine of 1941-42). Finally, the majority of the studies on the impact of

\footnotetext{
${ }^{1}$ See Currie (2009) and Almond and Currie (2011) for extensive reviews of the economic literature on the analysis of the fetal origins hypothesis.

${ }^{2}$ A few exceptions include Currie and Schwandt (2013) who show that seasonal influenza is associated with preterm delivery and several studies demonstrating the impact of air pollution on birth outcomes (e.g., Currie and Neidell, 2005; Currie, Neidell, and Schmeider, 2009; Currie and Walker, 2011).
} 
impairments in fetal development focuses on birth outcomes, while effects that may manifest themselves at later stages in life, especially in adulthood, are relatively under-researched. ${ }^{3}$ In this paper, we consider the labor market impacts of nutritional disruptions in utero among immigrant Muslim males between 25-54 years of age living in Denmark, exploiting the month of Ramadan as a natural experiment. In particular, we examine whether Muslim men living in Denmark who had been exposed to Ramadan during specific months of gestation differ in their labor market outcomes from Muslim men who had not been exposed to Ramadan in utero. ${ }^{4}$

Our analysis considers only men because among Muslims living in Denmark, women have a particularly low and unstable labor market attachment with frequent interruptions. ${ }^{5}$ Furthermore, for example, only 43 percent of Muslim women aged 25-54 are employed compared to 57 percent of Muslim men. In contrast, native Danish men and women have employment rates of 86 and 84 percent, respectively. Therefore, not only do native Danes have much higher rates of employment than Muslims, but the gap between men and women is also much narrower. Using data drawn from the administrative records of various Danish registries,

\footnotetext{
${ }^{3}$ Indeed in their discussion of promising avenues for future research, Almond and Currie (2011) highlight that the long-term effects of these experiments have not been fully determined. They thus point to the importance of identifying the long-term effects of relatively less extreme events as an avenue for future research, which could have serious policy implications.

${ }^{4}$ While the vast majority of Muslims in Denmark are immigrants or descendant there are only approximately 2,000 Muslim converts among native Danes (Bonke and Schultz-Nielsen, 2013). Thus in the following we use the term "Muslim immigrants" and "Muslims" interchangeably.

${ }^{5}$ The roles expected from or assigned to Muslim women in their communities may also be different from those of native Danish women. Accordingly, being employed need not necessarily be interpreted as a positive outcome, but rather be an indication of a poor financial situation. For example, on one hand Muslim women who have poorer health as a result of being exposed to Ramadan in utero may find it difficult to work. On the other hand, these women may also have poorer marriage prospects in terms of spousal income, an effect that may then exert pressure on them to seek jobs, including even low-paying ones.
} 
we examine a full spectrum of labor market outcomes, including employment status, annual salary, hourly wage rate, and annual hours of work. ${ }^{6}$

Ramadan is the holiest month in Islam, during which healthy Muslims are expected to refrain from eating and drinking between sunrise and sunset. Therefore, any potential changes in dieting behavior among Muslim pregnant women during Ramadan may have significant implications for their offspring. It is important to note that fasting during Ramadan is not unconditionally obligatory. For example, those who are acutely ill, who are travelling, who are menstruating or who are pregnant can postpone the Ramadan fast. However, there is an abundance of anecdotal and survey evidence to suggest that many pregnant women do in fact decide to observe the fast, citing a number of reasons, including local tradition, cultural expectations, and familial pressure (Leiper and Molla, 2003; Almond and Mazumder, 2011). ${ }^{7}$ Our research design represents a natural experiment under the assumption that the timing of Ramadan is exogenous to the timing of pregnancy (Almond and Mazumder, 2011; van Ewijk,

\footnotetext{
${ }^{6}$ We also considered the employment rates of a sample of immigrants to Denmark from predominantly non-Muslim countries. To come up with a control group resembling the group of Muslim immigrants as closely as possible, we eliminated immigrants coming from North American and Northern European countries. The rates of employment for the group of immigrants from non-Muslim countries are 69 percent among men and 62 percent among women. These figures are again considerably higher and also closer to each other than those for the Muslim group, indicating that the group of non-Muslim women differs significantly from the group of Muslim women. Despite these concerns, we estimated our empirical models for the female sample. Confirming our predictions, the results did not produce a systematic picture for the impact of intrauterine exposure to Ramadan on labor market outcomes among Muslim women. There appears to be a $7^{\text {th }}$ month effect on their likelihood of employment, but the estimate is not statistically significant at conventional levels. Again, the equivocal effect on employment is not surprising given their low employment rate to begin with. Therefore, outcomes related to compensation are more likely to be a better indicator of labor market performance among Muslim women since they are conditioned on employment. In fact, we obtained more precisely estimated effects around the months of the second and third trimesters for the models of annual salary and wage rate. However, we do not present results for females due to concerns described earlier. The full results from these analyses are available upon request.

${ }^{7}$ Almond and Mazumder (2011) provides a summary of the anecdotal and survey evidence that suggests that fasting is the norm rather than the exception among pregnant Muslim women. For example, estimates of fasting obtained in countries such as England, Gambia, Iran, Singapore, the United States, and Yemen range from 70 to 90 percent. The prevalence of fasting during pregnancy among Muslim women is unknown. However, anecdotal evidence obtained from pregnant Muslim women in Danish hospitals and provided to us by Dr. Jacob Alexander Lykke of Copenhagen University Hospital Hvidovre suggests that fasting during pregnancy in this population is not uncommon.
} 
2011). ${ }^{8}$ It is important to note that Ramadan follows the Islamic Calendar, which is 11 days shorter than the Gregorian calendar. This means that Ramadan’s occurrence moves forward 11 days each year. Therefore, with data spanning 30 birth cohorts, one can tease out any selection effect that might be associated with seasonality of birth from the effect of exposure to Ramadan in utero. In robustness analysis, we also make use of data from a sample of non-Muslim immigrants to estimate difference-in-difference models in an attempt to eliminate any remaining unobserved heterogeneity or artifacts of seasonality.

It must be noted that we do not observe fasting behavior in our data. Therefore, our empirical results would represent an intent-to-treat effect (ITT), producing not the impact of actual fasting during Ramadan, but rather the effect of exposure to Ramadan. An advantage of estimating an ITT as opposed to an average treatment effect on the treated (ATT) is that an ITT allows us to avoid the difficulty of addressing the endogeneity of the decision to fast. By estimating an ITT, we implicitly assume that Muslim mothers who fasted during pregnancy are different from those who did not in both observable and unobservable ways (Almond and Currie, 2011). To the extent that some pregnant Muslim women fast during Ramadan and some do not, the estimates obtained in our study constitute a lower (or conservative) boundary for the true effect of fasting. ${ }^{9}$

In addition to constituting a fresh contribution to the broad literature on the analysis of the fetal origins hypothesis, our paper also extends the body of evidence available from existing Ramadan studies in a number of unique dimensions. First, this is the first study to focus on long

\footnotetext{
${ }^{8}$ Previous studies have found no evidence that pre-determined maternal and paternal characteristics are systematically related to the timing of conception relative to Ramadan (Almond and Mazumder, 2011; Almond, Mazumder, and van Ewijk, 2011; van Ewijk, 2011).

${ }^{9}$ Note that if we had information about the exact proportion of Muslim women who fast during Ramadan, the true effect could be obtained by multiplying our estimates with the inverse of the rate of fasting women (Almond, Mazumder, van Ewijk, 2011).
} 
term effects of Ramadan exposure in the setting of a developed country. The only other evidence of Ramadan exposure in utero on labor market outcomes stems from analyses of Census data from Iraq, Uganda (Almond and Mazumder, 2011), and survey data from Indonesia (Majid, 2013). However, there are significant differences between Denmark and these countries in the nature of labor market conditions. For example, a significant fraction of the labor force is employed in the agricultural sector in those countries. According to data from the World Bank, the share of total employment in agriculture is 30 percent in Iraq, 36 percent in Indonesia, and 66 percent in Uganda in comparison to only three percent in Denmark. ${ }^{10}$ Furthermore, these countries are likely to have a much larger proportion of their labor force in self-employment than Denmark. ${ }^{11}$ Second, this is the first study to use individual administrative records as measures of labor market outcomes. This is an important novelty over the previous Ramadan studies, which were based on cohort analyses using either survey or Census data. Administrative data have clear advantages over other types of data in terms of both accuracy and coverage. Third, we are also able to analyze a wide range of labor market outcomes, including measures of labor supply both at the intensive and extensive margins as well as compensation.

We wish to stress that the implications of our analysis are not solely relevant for Muslim communities, but extend to a much broader audience. This is because susceptibility to milder forms of nutritional disruptions is frequently experienced in many populations across the western world. Our analysis is particularly policy-relevant for women living in developed countries,

\footnotetext{
${ }^{10}$ See http://data.worldbank.org/indicator/SL.AGR.EMPL.ZS.

${ }^{11}$ In fact, being an "employee" may be indicative of an inferior socio-economic status when compared to being selfemployed or being a landowner. To support this point, Almond and Mazumder (2011) show that among Iraqi males, homeowners are less likely to be employed than non-homeowners, which they argue as evidence of a negative relationship between employment status and economic status. These differences may be the source of inconsistent results on their employment results obtained in their paper.
} 
where meal-skipping, dieting (especially prior to pregnancy recognition), and morning sickness are common phenomena (Currie, 2011; Almond and Mazumder, 2011). ${ }^{12}$

\section{Background}

The potential mechanisms through which nutritional disruptions to the intrauterine environment can influence health at birth and in the long term are extensively debated in the medical literature although a consensus does not appear to exist. ${ }^{13}$ One explanation that is particularly relevant in the context of Ramadan fasting refers to a series of metabolic changes in the intrauterine environment called "accelerated starvation" that are caused by fasting. It is argued that accelerated starvation may be responsible for elevated levels of ketones and reductions in glucose (Metzger, 1982; Prentice et al., 1983), which have been linked to poor birth outcomes (Hunter and Sadler, 1987, Moore et al, 1989; Rizzo et al., 1991; Gluckman and Hanson, 2005; ter Braak et al., 2002; Scholl et al., 2001). ${ }^{14}$

Another hypothesis offered for the long-term effects of nutritional disruptions in utero is fetal origins. As mentioned earlier, poor environmental conditions in utero can lead to poor health in the long term through a process called fetal reprogramming. Interestingly, this theory suggests that the fetus may have the ability to adapt to changes in the intrauterine environment by reprogramming itself, which may be beneficial for survival in the short term, but raises the risk of disease in the long term. For reasons that are not yet completely understood, the effects appear to be influenced by the stage of fetal development during which the exposure occurs. In a

\footnotetext{
${ }^{12}$ Aside from generalizability, there are close to two billion Muslims in the world and millions of pregnant Muslim women fast each year.

${ }^{13}$ Excellent summaries of these mechanisms in the economics literature can be found in Almond and Mazumder (2011), Almond, Mazumder, and van Ewijk (2011), van Ewijk (2011), and Majid (2013).

${ }^{14}$ See Almond and Mazumder (2011) for a detailed discussion of the literature linking these metabolic changes to the physical and cognitive health of the offspring. $\square$
} 
review of findings on the effects of exposure to the Dutch famine during pregnancy on infant characteristics and health of the adult offspring, Painter et al. (2005) conclude that there are significant adverse health effects, which vary according to the timing of the exposure to famine. For example, exposure in early pregnancy appears to be associated with coronary heart disease, obesity, raised lipids, altered clotting, and increased obesity, while exposure in mid and late pregnancy is associated with obstructive airways disease and impaired glucose tolerance, respectively. In addition to effects on physical health, studies have also documented ill effects of exposure to the Dutch famine on mental health of the adult offspring, which also vary by the timing of the exposure (Susser and Lin, 1992; Hoek, Brown, and Susser, 1998; Susser et al., 1996; Hulshoff et al., 2000; Brown et al., 2000a). The evidence suggests that exposure to famine in late pregnancy is associated with elevated risk of major depressive disorder, especially among males (Brown et al., 1995; Brown et al., 2000b). With regard to infant characteristics, studies found that exposure to famine in both mid and late pregnancy is associated with lower birth weight and length, smaller head circumference and ponderal index compared to non-exposure (Stein, Ravelli, and Lumey, 1995; Stein et al., 2004).

The above discussion also serves as a motivational background for our analysis of the impact of intrauterine exposure to nutritional disruptions on labor market outcomes. The insights for this motivation can also be gained by a simple formal model first developed by Heckman (2007), but later adapted by Almond and Currie (2011) to suit to the conceptualization of the fetal origins hypothesis. This model clearly outlines the link between prenatal conditions and both health and human capital formation throughout the course of life. One basic proposition that flows logically from the model is that if there are indeed significant health impacts associated with exposure to nutritional disruptions in utero, these effects might also extend to outcomes in 
other domains such as the labor market. This proposition is consistent with the sizeable and compelling literature demonstrating that fetal health and early life conditions have profound effects on adult well-being through influencing human capital formation and adult health (Cunha and Heckman, 2007; Deaton, 2002 Currie, 2009; Cunha, Heckman, and Schennach, 2010). This literature furthermore suggests that the effects of fetal conditions might be larger than those of postnatal conditions (Almond and Currie, 2011).

Previous studies of Ramadan exposure conducted outside the field of economics have usually taken the approach of comparing the outcomes of Muslims whose mothers report having fasted during pregnancy to the outcomes of children of either other Muslim women who do not report having fasted or of non-Muslim women (e.g., Cross et al., 1990; Malhotra et al., 1989; Azizi et al., 2004). The evidence from these studies is primarily correlational because women who fast during pregnancy are likely to be different from those who do not in ways that are correlated with the outcomes analyzed (Almond and Mazumder, 2011; Majid, 2013).

Our study is in the same vein as a recent wave of research conducted by economists, who have considered the month of Ramadan as a natural experiment in their attempt to estimate the impact of intrauterine exposure to malnutrition on birth and later life outcomes. The pioneering study in this literature is Almond and Mazumder (2011). Using data on births to Arab parents in Michigan, USA, these authors find that exposure to Ramadan is associated with reduced birth weight and a decrease in the number of male births. They also find large effects on the probability of disability among adults, using census data in Iraq and Uganda. Finally, the investigation in Almond and Mazumder (2011) into non-health outcomes, including employment, home ownership, and literacy produces typically smaller and somewhat inconsistent results. 
Another non-health outcome considered in the literature of Ramadan studies is education. Using data from Britain, Almond, Mazumder, and van Ewijk (2011) show that test scores are lower among Pakistani and Bangladeshi students who were exposed to Ramadan in utero than among those with no in utero exposure. Since the authors had data on only ten cohorts, they had to utilize a difference-in-difference strategy to eliminate the likely seasonality effects for educational outcomes. In doing so, they constructed a control group of students from the Caribbean.

Aside from these two papers, the only other evidence on the impact of Ramadan exposure in utero comes from two separate studies, both of which use data from the Indonesian Family Life Survey. In the first one, van Ewijk (2011) shows that Indonesian Muslims who were prenatally exposed to the month of Ramadan are more likely to have poorer general health and to develop symptoms of coronary heart disease and type 2 diabetes than their counterparts who were not prenatally exposed to Ramadan. In the second study, Majid (2013) uses survey data from Indonesia to show that adults who were exposed to the month of Ramadan in utero are more likely to be self-employed and work fewer hours than those who were not. It is not clear whether results from a predominantly Muslim country like Indonesia, where over 60 percent of all employees live in rural areas, can be generalized to Muslims living in a high income Western country like Denmark. Furthermore, the evidence in that paper is based on survey data with selfreported measures on outcome variables. ${ }^{15}$ Our paper thus represents a unique contribution to this growing literature by focusing on a broad range of labor market outcomes and using administrative data from immigrants settled in a western society.

\footnotetext{
${ }^{15}$ Also outcomes of males and females are analyzed jointly in that paper. This is despite the evidence of considerable differences in the patterns of behavior with respect to the level and types of employment between males and females in Indonesia. For example, males are most likely to work as employees, while females are most likely to work as unpaid family workers (Hasoloan, 2006).
} 


\section{Data}

Our data are drawn from several Danish registers that are maintained by Statistics Denmark. The employment indicator is extracted from the Register-based Labor Force Statistics (RAS statistics). ${ }^{16}$ The RAS statistics describes the Danish population's attachment to the labor market at the end of November in each year. The categories of labor market affiliation provided in the RAS statistics closely follows the international guidelines specified by the International Labour Organization (ILO). Both the validity and the coverage of the RAS statistics have been shown to be high (Petersson, Baadsgaard, and Thygesen, 2011). We construct a binary indicator for employment for individuals who are categorized as an employee in the RAS statistics in 2008, excluding self-employed persons and assisting spouses. ${ }^{17}$ Given the way the RAS statistics is structured, our employment indicator refers to the last week of November. The data on salary income come from the Income Statistics Register. ${ }^{18}$ The data on annual hours of work from 2008 are available from the eIncome Register. ${ }^{19}$ These registers include information on anyone, who has submitted a tax return to the Danish Tax Administration. Finally, the wage rate is calculated

\footnotetext{
${ }^{16}$ See htttp://www.dst.dk/declarations/848.

${ }^{17}$ Note that the annual hours of work - one of our outcome measures - is not available for years prior to 2008. Furthermore, it is important to note that the global financial crisis did not spare Denmark, pushing its economy into multiple periods of recession, first in the third quarter of 2008 (which lasted for 12 months), second in the third quarter of 2011 (which lasted for 6 months) and again in the fourth quarter of 2012 (which lasted for 6 months) (OECD, 2014). Although, the recession initially affected the construction sector, in which very few immigrants are employed, it spread to other parts of the economy including the public sector from the beginning of 2009. Especially hard hit by these economic downturns have been the immigrants whose labor market outcomes have deteriorated significantly and have not recovered much since then. Therefore, the post-2008 period may not reflect the labor market behavior of a typical immigrant, which may complicate the interpretation of results from an analysis using data from those years. Despite these concerns, we have estimated all of our models using data from subsequent years including 2009 and 2010. The results for these years are mostly similar, although the coefficients in some of the outcome models are less precise, possibly due to reasons explained above. These results are available from the authors upon request.

${ }^{18}$ See htttp://www.dst.dk/declarations/94760.

${ }^{19}$ See http://www.dst.dk/declarations/148522.
} 
on the basis of salary income in 2008 divided by hours of work in that year. Note that all of these data are based on official reports by employers (Baadsgaard and Quitzau, 2011).

We have limited our sample to male immigrants from Muslim and non-Muslim countries residing in Denmark between the ages of 24 and 55 in 2008. We excluded individuals who were self-employed from our analysis since there is no reliable wage information for individuals in this group in the Danish registers. In addition, we observed spikes in the proportion of individuals reporting birthdays as January $1^{\text {st }}$ and July $1^{\text {st }}$. Note that misreporting is only possible among first generation Muslim immigrants because we have the exact birthday information for the descendants. To eliminate measurement error due to heaping, we excluded first generation Muslim immigrants with a birthday on January $1^{\text {st }}\left(1,704\right.$ persons) and July $1^{\text {st }}(1,049$ persons) from our analysis. These criteria have resulted in an analysis sample of 38,637 individuals. ${ }^{20} \mathrm{We}$ categorized an individual as Muslim if he/she or his/her parents migrated from a country with a population comprised of at least 90 percent Muslims. ${ }^{21}$ According to this criterion, 29.6 percent of Muslim immigrants in Denmark are of Turkish origin, followed by Iraqis (13.4 percent), Iranians (11.9 percent), Palestinians (11.1 percent), and Pakistanis (10.4 percent).

In Table 1, we present means for our analysis sample. Approximately, 57 percent of Muslim males between the ages of 24 and 55 in Denmark are employed. The average number of annual hours of work in our sample is 1,432 and the average annual salary income is 250,469 DKK. ${ }^{22}$ Finally, the hourly wage rate is 172.4 DKK. As expected, there are sharp differences in the labor market outcomes between native Danish males and immigrant males from Muslim

\footnotetext{
${ }^{20}$ Note that the analysis sample for each of our outcome models differs slightly in size due to missing observations on outcome variables.

${ }^{21}$ These countries include Turkey, Algeria, Cameroon, Gambia, Mali, Morocco, Tunisia, Mauritius, Senegal, Somalia, Yemen, Afghanistan, Iran, Iraq, Jordan, Palestine, Maldives, Oman, Pakistan, Syria, Djibouti, Azerbaijan, Uzbekistan, Turkmenistan, and Tajikistan.

${ }^{22} 1 \mathrm{DKK}$ is about $\$ 0.17$.
} 
countries. For instance, the employment rate among similarly aged native Danish males is 0.86 . Similarly, the average number of hours worked annually is over 1,600 for the native Danish male sample. The gap is similarly wide for the compensation outcomes with native Danish males earning 380,579 DKK annually and 219.9 DKK per hour. There are a multitude of factors offered as potential explanations for the wide differences in labor market attachment between Muslims and native Danes including low level of education, discrimination, language barriers, and cultural factors (Bonke and Schultz-Nielsen, 2013).

We also have data on the highest level of educational attainment drawn from the Education Registry, which enables us to highlight the differences in education between Muslim immigrants and the native Danish population. The average length of education among Muslims in Denmark is about 138 months, which is again considerably lower than that of native Danish males who have close to two additional years of education. The average Muslim male in the sample is about 41 years old and has been in Denmark for over 15 years. Over 91 percent of Muslims in Denmark were born outside Denmark, so the remaining 9 percent are represented by descendants.

For each male Muslim immigrant in our dataset, we have constructed binary indicators to determine whether the beginning of Ramadan coincided with any of the nine months of gestation. The algorithm that we used to determine intrauterine exposure to Ramadan is illustrated in Table 2. We assume that all individuals have a normal gestation period of 266 days. In addition to generating indicators for each of the nine months of pregnancy, we also constructed a "Month 0" indicator, which represents individuals who were conceived during Ramadan. Individuals who are not in any of these categories are divided into groups. The first group contains individuals who were "definitely not exposed" if they were conceived more than 
14 days after Ramadan. The second group referred to as "probably not exposed" includes those who were conceived within 14 days following the end of Ramadan. Note that our categorization of the months of exposure to Ramadan is identical to that employed by Almond, Mazumder, and van Ewijk (2011). Inevitably, our assumption of a normal gestation period of 266 days for all mothers would introduce some measurement error to our assignment rule to the extent that some births will be preterm and some pregnancies will last longer than the full term. Additional measurement error in the assignment would also result from the possibility that the date of birth is misreported for some individuals. ${ }^{23}$ As shown in Table 1, 13 percent of males in our sample were definitely not exposed to Ramadan in any months of the gestation period and another four percent were probably not exposed.

\section{Empirical Framework}

With data covering 30 birth cohorts, we rely on the sample of Muslims only and attempt to remove confounding factors using month of birth fixed effects as well as a set of individual and neighborhood characteristics. Controlling for month of birth fixed effects may be particularly important in our context because previous research has established that season of birth is associated with adult health and occupational outcomes (Buckles and Hangerman, 2013;

\footnotetext{
${ }^{23}$ Misreporting in the date of birth is possible only for first generation immigrants for whom the information on the date of birth is self-reported. Since descendants are all born in Denmark, birth date information for them is derived from the official records, and thus is free of misreporting. Note that individuals who are in the "Definitely not exposed" category would be misclassified only if their period in utero exceeded 280 days. In that case, these individuals should have been labeled as exposed in the month we define as month 0 . However, gestations lasting longer than 280 days are rare (Kieler et al., 1995). We have tested the measure of overlap with Ramadan calculated from date of birth on a sample of descendants with information on exact gestational age. Here we find that the cases in the "Definitely not exposed" category calculated from date of birth are also definitely not exposed when we use the exact gestational age to calculate overlap with Ramadan. For the other categories with cases in which Ramadan overlaps with months $1,2 \ldots 9$, the categories calculated using date of birth are similar to the categories calculated using exact gestational age. More specifically, approximately $75 \%$ of the cases with a specific month overlap calculated from birth are in the same month category when we use gestational age to calculate overlap with Ramadan in utero. Approximately 25 percent of the cases with a specific month overlap calculated from birth are placed in the month categories close to this month when we use gestational age to calculate overlap with Ramadan in utero.
} 
Doblhammer and Vaupel, 2001; Costa and Lahey, 2005; Currie and Schwandt 2013). It is possible to include both month of birth dummies and the indicators of month of exposure to Ramadan in utero in the models at the same time because Ramadan follows the Islamic Calendar, which is 11 days shorter than the Gregorian calendar.

Our empirical strategy to estimate the effect of Ramadan exposure in utero on labor market outcomes can be expressed by the following empirical model:

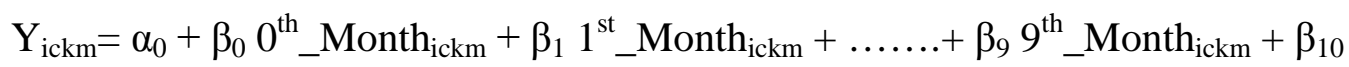

Probably_NE $\mathrm{ickm}_{\mathrm{i}}+$ month $_{\mathrm{m}}+$ country $_{\mathrm{c}}+$ community $_{\mathrm{k}}+\mathbf{X}_{\mathrm{ickm}} \beta_{11}+\varepsilon_{\mathrm{ickm}}$,

where $Y_{\text {ickm }}$ is one of our four outcome measures (binary employment, logarithm of annual salary income, logarithm of hourly wage rate, and logarithm of annual hours of work) for individual i from country c living in community $\mathrm{k}$ and born in month $\mathrm{m}$. Our variables of interest

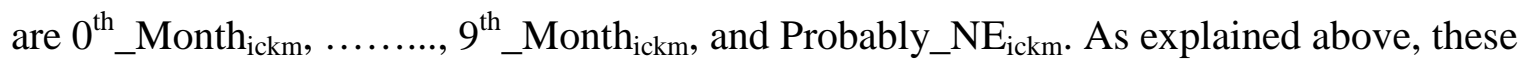
variables indicate whether Ramadan began during the given month of pregnancy. Note that

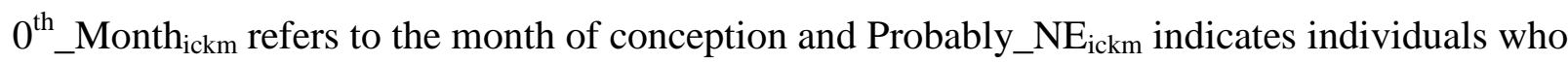
were probably not exposed to Ramadan in utero. The excluded category in our regressions contains those who are categorized as "Definitely not exposed", so the effects are interpreted relative to this group. We also control for month of birth fixed effects $\left(\right.$ month $\left._{\mathrm{m}}\right)$, country of origin fixed effects (countryc), and community of current residence fixed effects (community ). $^{2}$ Finally, we control for a vector of individual characteristics represented by $\mathbf{X}_{\mathrm{ickm}}$. These include a binary indicator variable for whether the Muslim male immigrant was born in Denmark or in the country from which his parents emigrated, year since migration and its squared term, and age in 
flexible functional form with its polynomials up to the fourth order. ${ }^{24}$ The $\varepsilon_{\text {ickm }}$ is an idiosyncratic error term. We estimate equation (1) using ordinary least squares, adjusting standard errors for clustering at the community level. The coefficients of interest in equation (1) are $\beta_{0}$ to $\beta_{10}$.

Since we have access to administrative records on the labor market outcomes of all individuals living in Denmark, we can in principle utilize data on immigrants from non-Muslim countries to employ a difference-in-difference strategy in a further attempt to tease out any effects due to seasonality. However, it is not clear whether non-Muslim immigrants in Denmark would be a good comparison group. For example, a large proportion of non-Muslim immigrants living in Denmark came from western countries such as France, Sweden, Germany, the Netherlands, the United States, and Canada. These immigrants are significantly different from Muslims immigrants in socio-economic characteristics as they tend to be much more highly educated, with substantially higher income, and have a stronger and more stable labor market attachment. Many of these individuals have migrated to Denmark for reasons such as marriage, job transfer, and pursuing higher education. In contrast, most Muslim immigrants come to Denmark for mainly economic reasons or to seek refuge from political or civil conflicts in their home countries.

Keeping these limitations in mind, we still discuss estimates in the results section from a robustness analysis, in which we use a sub-sample of non-Muslim immigrants as a control group in a difference-in-difference framework. We categorize a country as non-Muslim if less than 15 percent of its population is made up of Muslims. The use of such a cut-off is necessitated by the fact that in most countries part of their population is Muslim. Furthermore, we have eliminated immigrants from North America and Northern Europe, who would constitute a poor control

\footnotetext{
${ }^{24}$ Entering age in a fully non-parametric form did not change our results.
} 
group for reasons explained above. It is important to note that countries like Bulgaria and Russia with Muslim populations of 13.4 percent and 11.7 percent, respectively, are included in the control group under this criterion. ${ }^{25}$ In addition to these countries, the largest denominations of non-Muslim immigrants come from countries such as Poland, Vietnam, Thailand, Philippines, China, and Sri Lanka. The characteristics of immigrants from these non-Muslim counties are displayed in Table 3. As illustrated in the table, non-Muslim male immigrants, as defined under the above criteria, still have a stronger labor market attachment, as measured by employment, working hours, wage rate, and annual salary income, than Muslim immigrants. Consistent with the differences in labor market outcomes, non-Muslim immigrants have also had more years with education than Muslim immigrants (154 months versus 138 months). The non-Muslim males are slightly younger on average than their Muslim counterparts and they have been living in Denmark for a shorter period since immigration than Muslim immigrants. Accordingly, a higher percentage of non-Muslim males are first generation immigrants, i.e., they were born outside Denmark, than Muslim males. Finally, Muslim immigrants more often live in larger cities such as Copenhagen, Aarhus, Odense, and Aalborg than non-Muslim immigrants.

To implement the difference-in-difference strategy, we fully interact each regressor (except for community and country of origin fixed effects) in equation (1) with an indicator for being Muslim. This estimation strategy produces the impacts on Muslims for whom Ramadan coincided with their period in utero compared to Muslims with no in utero exposure to Ramadan, relative to non-Muslim immigrants. Note that the difference-in-difference strategy does not require the pregnancy experiences of Muslim and non-Muslim women to be identical, but rather requires the month of Ramadan to have no effect on the offspring of non-Muslim women and

\footnotetext{
${ }^{25}$ Muslim Populations by Country. The Future of the Global Muslim Population. Pew Research Center. http://www.pewforum.org/2011/01/27/table-muslim-population-by-country/.
} 
that the labor market outcomes of Muslim and non-Muslim immigrants are parallel between months in utero that coincided with Ramadan and those that did not. A particular advantage of using non-Muslim immigrants as an additional control group is that it accounts for any confounding caused by the seasonal effects of birth (or conception) (Doblhammer and Vaupel, 2001; Almond, Mazumder, and van Ewijk, 2011). The difference-in-difference strategy employed in our context is similar to the one used by Almond, Mazumder, and van Ewijk (2011), which considers Pakistani and Bangladeshi immigrants in England as the treatment and individuals from Caribbean as the control group to study the effect of intrauterine exposure to Ramadan on children's test scores at age seven. We could also use native Danes as a control group in the difference-in-difference strategy. However, native Danes, with much stronger attachment to the labor market, are quite a different group from the other two.

\section{Results}

The results from our empirical analysis are presented in Table 4. To economize on space, we only report the figures on our "month of exposure" indicators, but full results are available from the authors upon request. The excluded category contains those who are classified as “certainly not exposed," and thus all effects are relative to this group. These indicators represent the effects of Ramadan on Muslims starting in each month of pregnancy compared to Muslims with no in utero exposure. In Column I, we present the estimates from the employment model. Column II displays the results on the logarithm of annual salary income and Column III shows the estimates for the logarithm of the hourly wage model. Finally, we present the estimates for the logarithm of the annual hours of work in Column IV. 
The employment results presented in Column I of Table 4 indicate that being exposed to the month of Ramadan in the $7^{\text {th }}$ month of gestation is associated with a 2.6 percentage point decrease in employment, which is statistically significant at the 5 percent level. Given the mean employment rate of 56.7 percent among Muslim males, this estimate translates into a non-trivial effect size of 4.6 percent. It should be remembered that these results represent a lower boundary since only a fraction of pregnant Muslim women observe the Ramadan fast.

The estimates for the model of annual salary income shown in Column II are consistent with the employment results. Specifically, Muslim males, whose mothers were in the $7^{\text {th }}$ month of gestation when the month of Ramadan had begun, have an annual income that is 5.3 percent less than those whose period in utero had not overlapped with the month of Ramadan. Given the annual salary income of 250,469 DKK among Muslim males in 2008, this estimate indicates an effect size of about DKK 13,000.

Focusing next on the results for the model of hourly wage rate shown in Column III, we detected no $7^{\text {th }}$ month effect in contrast to the case for employment and annual salary income. In fact, the estimates on all indicators of exposure for months 1 to 9 are insignificant both statistically and economically. Somewhat surprisingly, however, those who were in the "probably not exposed" and " 0 th month" categories earn a lower wage rate than those who were definitely not in utero during Ramadan. Interestingly, Almond, Mazumder, and van Ewijk (2011), whose assignment rule for exposure to Ramadan is identical to ours, find similar negative and statistically significant results for these two indicators. In examining this further, they find some evidence to indicate that Muslims who were in utero during these periods are of lower socio-economic status proxied by Free School Meal status. One possible explanation is that children who were conceived during Ramadan or within the 14 days following the end of 
Ramadan may come from families that differ in their socio-economic characteristics and these differences may manifest themselves in their sexual practices or levels of Ramadan observance (Almond, Mazumder, and van Ewijk, 2011).

Although Islam does not prohibit sexual intercourse between spouses during Ramadan as long as it takes place outside the fasting hours, there may be a negative selection effect associated with conception during Ramadan. For example, if these individuals are also more likely to engage in certain behaviors such as smoking and alcohol consumption during pregnancy, then this may serve as a potential explanation for the negative coefficient on the " 0 "th month” indicator. However, our data do not allow us to investigate this hypothesis. A similar argument can be made for the negative effect for those who were conceived within 14 days after Ramadan. Note that some of these individuals might have been conceived during the month of Ramadan in so far as their gestation might have lasted longer than 266 days. Then calculating backwards from the date of birth, some of these individuals might have actually been conceived during Ramadan.

The only measure of socio-economic status that we could use to examine the issue of selective timing of pregnancy is maternal education, which is only available to us in the descendant sample. Indeed the individuals in the "probably not exposed" category are more likely to have mothers with no formal education than other categories. However, the difference is not statistically significant at conventional levels likely due to the much smaller sample size among descendants. Taken together, this exercise produced no clear evidence for selective timing of pregnancy based on education. Notably, we did not find any evidence to indicate that mothers whose pregnancy overlapped with Ramadan during the $7^{\text {th }}$ month of gestation differ with respect to maternal education from those whose pregnancy did not overlap with Ramadan. 
Therefore, it is unlikely that the $7^{\text {th }}$ month effect that we observe for employment and salary income outcomes are driven by negative selection.

Finally, we present results for the effect of Ramadan exposure in utero on annual hours of work in Column IV of Table 4. Consistent with the earlier findings, the estimate on the $7^{\text {th }}$ month exposure stands out as the largest estimate in magnitude and with statistical significance at the 10 percent level. The coefficient of -0.047 percent translates into an effect size of about 67 hours per year. Aside from this result, the most precisely estimated coefficient is the "probably not exposed" category, and surprisingly with a positive sign ( $\mathrm{p}$-value=0.045). Note that the estimate on this indicator was positive, although insignificant, for the annual salary model, but negative and statistically significant at the 10 percent level for the hourly wage model. In light of the negative wage effect, one possible explanation for the positive effect on labor supply is that Muslim males attempt to make up for the reduced income by increasing their labor supply, possibly by working long shifts and overtime. In other words, this result is consistent with the notion that income effect dominates the substitution effect for Muslim males in this group.

The picture emerging from the results presented in Table 4 is that Ramadan exposure in utero tends to have negative effects for those exposed during and around the $7^{\text {th }}$ month of gestation on labor market outcomes measured by employment, annual salary, and annual hours of work. In other words, the results described thus far support the hypothesis that exposure to Ramadan in utero is associated with a penalty in the labor market that manifests itself in the form of a lower likelihood of employment, a lower salary, or reduced labor supply, but not necessarily a lower wage rate.

Robustness Analysis using Non-Muslim Male Immigrants as a Control Group 
Next, we present results from the difference-in-difference analysis using non-Muslim male immigrants as a control group. The estimates for each of the labor market outcomes are presented in Table 5 in the same order as they were in Table 4. We only show the estimates on the interaction terms between the Muslim indicator and our nine indicators of Ramadan exposure. These estimates represent the effects of Ramadan exposure on Muslim immigrants starting in each month of pregnancy compared to Muslims with no in utero exposure to Ramadan, relative to non-Muslim immigrants. The results for the employment outcome shown in Column I consistently point to negative effects of Ramadan exposure during the $3^{\text {rd }}$ trimester, i.e., the indicators for the $7^{\text {th }}, 8^{\text {th }}$, and $9^{\text {th }}$ months, with the largest effect in the $7^{\text {th }}$ month, although none of the estimates are statistically significant.

As illustrated in Column II of Table 5, the estimates for the logarithm of annual salary income again indicate a negative and statistically significant effect for male Muslims who were in the $7^{\text {th }}$ month of gestation when Ramadan began. Furthermore, the point estimate on the $7^{\text {th }}$ month indicator suggests that these individuals earn about 8 percent less than their counterparts who were definitely not in utero at the time of Ramadan. This finding is consistent with our main result presented in Table 4.

The results from the wage model as shown in Column III are not out of line with the results from our main specification presented in Table 4, i.e., none of the indicators for month of exposure are statistically significant. Furthermore, consistent with the Muslim-only analysis, the indicators on "Probably not exposed" and " $0^{\text {th }}$ Month" are still negative and larger in magnitude than other estimates. However, they are no longer statistically significant, which is possibly due to the ability to controlling for seasonal effects more effectively in the difference-in-difference analysis. 
Finally, we present the results for annual hours of work in Column IV. Again, we find effects rather similar to the results from the main specification presented in Table 4. In particular, the estimate on the $7^{\text {th }}$ month of exposure is negative and significant at the 5 percent level suggesting that Muslims males who were exposed to Ramadan in the $7^{\text {th }}$ month of gestation work about 7 percent fewer hours than those with no exposure to Ramadan, relative to male immigrants from non-Muslim countries. Interestingly, the estimate on the $8^{\text {th }}$ month exposure indicator is now also statistically significant and has the same magnitude as the coefficient on the $7^{\text {th }}$ month indicator.

To sum up, the results from the robustness analysis discussed above generally reaffirm our main finding that intrauterine exposure to Ramadan is associated with penalties in the labor market, as measured by likelihood of employment, earnings and labor supply. This is evidenced by the pattern whereby the signs on Ramadan exposure indicators are all negative when they are estimated with statistical significance. Aside from this pattern, the exact timing of the effects is also fairly consistent between the main results and those from the difference-in-difference analysis, despite the potential problems with the control group already mentioned.

\section{Potential Mechanisms}

The predictions of the fetal origins hypothesis may offer informative insights for our results. More specifically, one potentially key pathway through which a fetal insult such as nutritional disruptions may affect future labor market productivity may be health at birth and later in life, which in turn may influence human capital accumulation. To provide further insights into this proposition, we estimated a basic model on human capital accumulation, drawing on data on the highest level of educational attainment measured in months from the Education 
Register available to us from Statistics Denmark. Note that this is rather a crude measure since the educational attainment is based on self-reports for the over two-thirds of our sample who had not obtained any of their education in Denmark. Accordingly, none of the estimates on our indicators of month of exposure to Ramadan are estimated with statistical precision at conventional levels, which is consistent with the notion that the educational attainment is measured with considerable error. What we think is interesting and informative, however, is that the estimates on the $6^{\text {th }}$ and $7^{\text {th }}$ month indicators are the only coefficients that are negative in sign and in both cases the estimates are economically significant, which suggests that there may indeed be an adverse effect on human capital accumulation associated with intrauterine exposure to Ramadan around the $7^{\text {th }}$ month of gestation.

Next we considered whether health in adulthood is affected by prenatal Ramadan exposure as another potential channel by which our results could be explained. Disability is a good candidate for a measure of overall adult health and one that has also been considered in recent relevant literature. For example, Almond and Mazumder (2011) find a higher likelihood of disability for those who were exposed to Ramadan in the $9^{\text {th }}$ month of pregnancy using census data from Iraq and Uganda. Although we do not have a direct measure of disability in our dataset, we have an indicator for "early retirement” as a reason for figuring as not being employed in our register of labor force statistics (RAS). For the majority of individuals, this indicator reflects having some sort of physical or mental disability. The results from the estimation of our empirical model using the early retirement indicator as an outcome reveal statistically significant and positive effects associated with exposure to Ramadan in the $0^{\text {th }}$ and $7^{\text {th }}$ months of gestation. ${ }^{26}$ In particular, Muslim males who were exposed to Ramadan in the $7^{\text {th }}$

\footnotetext{
${ }^{26}$ The sets of full results from the analyses of educational attainment and disability are available from the authors upon request.
} 
month of gestation are 1.1 percentage points more likely to have retired early from the labor market. None of the other indicators were estimated with precision. Our results were very similar when we repeated this analysis using non-Muslim immigrants as a control in a difference-indifference framework. In particular, we obtained a statistically significant $7^{\text {th }}$ month estimate with an impact size of 1.2 percentage points, which is almost identical to the one from the model using the Muslim sample only.

The fact that we find more robust evidence of an impact on disability than education may also be revealing for our overall findings in this paper. Note that the overall findings are that exposure to Ramadan in utero is associated with a lower likelihood of employment, a lower salary, or reduced labor supply, but not necessarily a lower wage rate. This pattern is consistent with the explanation that the labor market penalty associated with Ramadan exposure may be more of a physical impact rather than a cognitive impact. In other words, those who are exposed to Ramadan are not able to work as many hours as others even though their marginal productivity is not necessarily any different.

\section{Conclusions}

Using administrative data from immigrants in Denmark, this paper provides the novel evidence on the impact of exposure to nutritional deficiency during fetal development on the labor market productivity of Muslim males. Our findings indicate that exposure to nutritional disruptions during a critical stage of fetal development has scarring effects expressed as poor labor market outcomes in adulthood. Specifically, exposure to Ramadan in utero results in a lower likelihood of employment, a lower salary, and reduced labor supply, but not necessarily a lower wage rate. Furthermore, our auxiliary analysis shows suggestive evidence that these results 
may partially be driven by increased disability and to a lesser extent by poor educational attainment among those who were exposed to Ramadan during this particular period in utero. It is important to highlight that the overlap between Ramadan and pregnancy appears to have adverse effects on the labor market outcomes of the adult offspring regardless of the specific month during which the exposure occurred. Moreover, whenever an impact is estimated with precision, the sign is negative. Also the effects appear to be strongest both statistically and economically around the $7^{\text {th }}$ month of exposure, which corresponds with the third trimester of pregnancy.

It is possible that individuals with biological deficits due to their exposure to Ramadan in utero may have received more favorable resources from society or their parents in an effort to mitigate their disadvantages. In that case, it is important to keep in mind that the results obtained in our study should be interpreted as the long-term biological and social effects of Ramadan exposure (Royer, 2009; Almond and Currie, 2011). This implies that the pure biological impact without remediation would be larger.

The findings in this paper have implications for societies in both Western and developing worlds where millions of babies continue to be born malnourished due to problems such as poverty. Therefore, the findings such as those obtained in our paper could be considered a basis for advocating interventions that provide benefits to pregnant mothers or families with young children (e.g., subsidized child care or kindergarten, parental leave policies, mentoring programs for children from low socio-economic backgrounds, etc.). One example is the federal Women, Infants, and Children (WIC) program in the United States, which provides grants to states for supplemental foods, health care referrals, and nutrition education for low-income pregnant and breastfeeding women, and to infants and children who are at nutritional risk. The results 
documented in this paper may suggest that a program like WIC would not only improve birth outcomes as shown in previous studies (e.g., Hoynes and Stevens, 2009), but could also have large impacts down the road to the extent that it improves maternal nutrition. Furthermore susceptibility to milder nutrient disruptions in utero is frequently experienced, even in developed countries, where meal skipping, dieting, and morning sickness are common, especially prior to pregnancy recognition (Currie, 2011; Almond and Mazumder, 2011). ${ }^{27}$

\footnotetext{
${ }^{27}$ Aside from generalizability, there are close to two billion Muslims in the world and millions of pregnant Muslim women fast each year.
} 


\section{References}

Almond, Douglas. 2006. "Is the 1918 Influenza pandemic over? Long-term effects of in utero Influenza exposure in the post-1940 US population." Journal of Political Economy no. 114 (4):672-712.

Almond, Douglas, and Janet Currie. 2011. "Killing me softly: The fetal origins hypothesis." The Journal of Economic Perspectives:153-172.

Almond, Douglas, and Bhashkar Mazumder. 2011. "Health capital and the prenatal environment: the effect of Ramadan observance during pregnancy." American Economic JournalApplied Economics no. 3 (4):56.

Almond, Douglas, Bhashkar Mazumder, and Reyn van Ewijk. 2011. Fasting During Pregnancy and Children's Academic Performance. National Bureau of Economic Research.

Azizi, Fereidoun, Hossein Sadeghipour, Behnam Siahkolah, and Nasrollah Rezaei-Ghaleh. 2004. "Intellectual development of children born of mothers who fasted in Ramadan during pregnancy." International journal for vitamin and nutrition research no. 74 (5):374-380.

Baadsgaard, Mikkel, and Jarl Quitzau. 2011. "Danish registers on personal income and transfer payments." Scandinavian journal of public health no. 39 (7 suppl):103-105.

Barker, DJ, AR Bull, C Osmond, and SJ Simmonds. 1990. "Fetal and placental size and risk of hypertension in adult life." BMJ: British Medical Journal no. 301 (6746):259.

Barker, David J. 1990. "The fetal and infant origins of adult disease." BMJ: British Medical Journal no. 301 (6761):1111.

Barker, David JP. 1995. "Intrauterine programming of adult disease." Molecular medicine today no. 1 (9):418-423.

Barker, David JP. 2002. "Fetal programming of coronary heart disease." TRENDS in Endocrinology \& Metabolism no. 13 (9):364-368.

Bonke, J, and ML Schultz-Nielsen. 2013. Integration blandt ikke-vestlige indvandrere (Immigration among non-western immigrants, English summary). University Press of Southern Denmark.

Brown AS, Susser ES, Lin SP, Neugebauer R, Gorman JM. 1995. Increased risk of affective disorder in males after second trimester prenatal exposure to the Dutch Hunger Winter of 1944-1945. Br J Psychiatry, 166:601-606

Brown, Alan S, Catherine A Schaefer, Richard Jed Wyatt, Raymond Goetz, Melissa D Begg, Jack M Gorman, and Ezra S Susser. 2000a "Maternal exposure to respiratory infections and adult schizophrenia spectrum disorders: a prospective birth cohort study." 
Schizophrenia Bulletin no. 26 (2):287-295.

Brown, A. S., van Os, J., Driessens, C., Hoek, H. W., \& Susser, E. S. 2000b. Further evidence of relation between prenatal famine and major affective disorder. American Journal of Psychiatry, 157(2), 190-195.

Buckles, K. S., \& Hungerman, D. M. 2013. Season of birth and later outcomes: Old questions, new answers. Review of Economics and Statistics, 95(3), 711-724.

Costa, D. L., \& Lahey, J. N. 2005. Predicting older age mortality trends. Journal of the European Economic Association, 3(2-3), 487-493.

Cross, JH, J Eminson, and BA Wharton. 1990. "Ramadan and birth weight at full term in Asian Moslem pregnant women in Birmingham." Archives of disease in childhood no. 65 (10 Spec No):1053-1056.

Cunha, F., \& Heckman, J. 2007. The technology of skill formation (No. w12840). National Bureau of Economic Research.

Cunha, Flavio, James J. Heckman, and Susanne M. Schennach. "Estimating the technology of cognitive and noncognitive skill formation." Econometrica 78.3 (2010): 883-931.

Currie, Janet and Matthew Neidell. 2005. “Air Pollution and Infant Health: What Can We Learn From California’s Recent Experience?” Quarterly Journal of Economics, 120(3): 10031030.

Currie, Janet. 2009. "Healthy, Wealthy, and Wise: Socioeconomic Status, Poor Health in Childhood, and Human Capital Development," Journal of Economic Literature, American Economic Association, vol. 47(1), pages 87-122, March.

Currie, Janet and Johannes F. Schmeider. 2009. "Fetal Exposures to Toxic Releases and Infant Health.” American Economic Review: Papers and Proceedings of the Annual Meeting of the American Economic Association, 99(2): 177-183.

Currie, Janet and Reed Walker. 2011. "Traffic Congestion and Infant Health: Evidence from EZPass.” American Economic Journals-Applied Economics.

Currie, Janet. 2011. Inequality at birth: Some causes and consequences. American Economic Review, 101 \#3, 1-22 (Ely lecture).

Currie, J., \& Almond, D. 2011. Human capital development before age five. Handbook of labor economics, 4, 1315-1486.

Currie, J., \& Schwandt, H. 2013. Within-mother analysis of seasonal patterns in health at birth. Proceedings of the National Academy of Sciences, 110(30), 12265-12270. 
Deaton, Angus.2002. Policy implications of the gradient of health and wealth. Health Affairs 21.2: $13-30$.

Doblhammer, Gabriele, and James W Vaupel. 2001. "Lifespan depends on month of birth." Proceedings of the National Academy of Sciences no. 98 (5):2934-2939.

Doyle, Orla, Colm P Harmon, James J Heckman, and Richard E Tremblay. 2009. "Investing in early human development: timing and economic efficiency." Economics \& Human Biology no. 7 (1):1-6.

Gluckman, P., \& Hanson, M. 2005. The fetal matrix: evolution, development and disease. Cambridge University Press.

Godfrey, Keith M, and David JP Barker. 2000. "Fetal nutrition and adult disease." The American Journal of Clinical Nutrition no. 71 (5):1344s-1352s.

Godfrey, Keith M, and David JP Barker. 2001. "Fetal programming and adult health." Public health nutrition no. 4 (2b):611-624.

Hasoloan, Maruli A. 2006. The Indonesian Labour Market: Indonesia Country Report. The OECD Forum on the restated OECD Jobs Strategy. http://www.oecd.org/fr/els/emp/37873500.pdf. Accessed on November 20, 2014.

Heckman, James J. 2007. "The economics, technology, and neuroscience of human capability formation." Proceedings of the national Academy of Sciences no. 104 (33):13250-13255.

Heijmans, B. T., Tobi, E. W., Stein, A. D., Putter, H., Blauw, G. J., Susser, E. S., ... \& Lumey, L. H. 2008. Persistent epigenetic differences associated with prenatal exposure to famine in humans. Proceedings of the National Academy of Sciences, 105(44), 17046-17049.

Hernández-Julián, Rey, Hani Mansour, and Christina Peters. In press. The effects of intrauterine malnutrition on birth and fertility outcomes: evidence from the 1974 Bangladesh famine. Demography.

Hoek, HW, AS Brown, and E Susser. 1998. "The Dutch famine and schizophrenia spectrum disorders." Social psychiatry and psychiatric epidemiology no. 33 (8):373-379.

Hoynes, H., Page, M., \& Stevens, A. H. 2011. Can targeted transfers improve birth outcomes?: Evidence from the introduction of the WIC program. Journal of Public Economics, 95(7), 813-827.

Hulshoff Pol, H. E., Hoek, H. W., Susser, E., Brown, A. S., Dingemans, A., Schnack, H. G., ... \& Kahn, R. S. 2000. Prenatal exposure to famine and brain morphology in schizophrenia. Schizophrenia Research, 41(1), 6. 
Hunter ES and Sadler,TW. 1987. beta hydroxybutyrate induced effects on mouse embryos in vitro. Teratology, 36:259 64.

Kieler, H, O Axelsson, S Nilsson, and U Waldenströ. 1995. "The length of human pregnancy as calculated by ultrasonographic measurement of the fetal biparietal diameter." Ultrasound in obstetrics \& gynecology no. 6 (5):353-357.

Leiper, JB, and AM Molla. 2003. "Effects on health of fluid restriction during fasting in Ramadan." European journal of clinical Nutrition no. 57:S30-S38.

Lumey, L. H., Stein, A. D., \& Susser, E. 2011. Prenatal famine and adult health. Annual review of public health, 32.

Majid, Muhammad Farhan. 2013. "The Persistent Effects of in Utero Nutrition Shocks Over the Life Cycle: Evidence From Ramadan Fasting." Unpublished manuscript.

Malhotra, Ashok, PH Scott, J Scott, H Gee, and BA Wharton. 1989. "Metabolic changes in Asian Muslim pregnant mothers observing the Ramadan fast in Britain." British Journal of Nutrition no. 61 (03):663-672.

Mansour, Hani, and Daniel I Rees. 2012. "Armed conflict and birth weight: Evidence from the al-Aqsa Intifada." Journal of Development Economics no. 99 (1):190-199.

Metzger, Boyd E, Rita A Vileisis, Veronica Ravnikar, and Norbert Freinkel. 1982. "' Accelerated starvation" and the skipped breakfast in late normal pregnancy." The Lancet no. 319 (8272):588-592.

Moore DCP, Stanisstreet M., and Clarke, CA. 1989. Morphological and physiological effects of beta-hydroxybutyrate on rat embryos grown in vitro at different stages. Teratology, 40: 237(51).

Neelsen, Sven, and Thomas Stratmann. 2011. "Effects of prenatal and early life malnutrition: Evidence from the Greek famine." Journal of Health Economics no. 30 (3):479-488.

OECD (2014). Quarterly National Accounts MetaData: Quarterly Growth Rates of real GDP, change over previous quarter. http://stats.oecd.org/Index.aspx?QueryId=350

Painter, Rebecca C, Tessa J Roseboom, and Otto P Bleker. 2005. "Prenatal exposure to the Dutch famine and disease in later life: an overview." Reproductive toxicology no. 20 (3):345-352.

Petersson, Flemming, Mikkel Baadsgaard, and Lau Caspar Thygesen. 2011. "Danish registers on personal labour market affiliation." Scandinavian journal of public health no. 39 (7 suppl):95-98.

Prentice, AM, Ann Prentice, WH Lamb, PG Lunn, and S Austin. 1983. "Metabolic consequences 
of fasting during Ramadan in pregnant and lactating women." Human nutrition. Clinical nutrition no. 37 (4):283-294.

Rizzo, Thomas, Boyd E Metzger, William J Burns, and Kayreen Burns. 1991. "Correlations between antepartum maternal metabolism and intelligence of offspring." New England Journal of Medicine no. 325 (13):911-916.

Royer, Heather. 2009. "Separated at girth: US twin estimates of the effects of birth weight." American Economic Journal: Applied Economics no. 1 (1):49-85.

Scholl, Theresa O, Sowers, MaryFran, Chen, Xinhua, \& Lenders, Carine. 2001. Maternal Glucose Concentration Influences Fetal Growth, Gestation and Pregnancy Complications. American Journal of Epidemiology, 154(6), 514-520.

Scholte, Robert, Gerard J Van den Berg, and Maarten Lindeboom. 2012. "Long-run effects of gestation during the Dutch hunger winter famine on labor market and hospitalization outcomes."

Stein, Zena, and Mervyn Susser. 1975. "The Dutch famine, 1944-1945, and the reproductive process. I. Effects on six indices at birth." Pediatric Research no. 9 (2):70-76.

Stein, Aryeh D., Anite CJ Ravelli, and LH Lumey. 1995. "Famine, Third-Trimester Pregnancy Weight Gain, and Intrauterine Growth: The Dutch Famine Birth Cohort Study.” Human Biology, vol. 67, no. 1, pp. 135-150.

Stein, Aryeh D., PA Zybert, M van der Bor, and LH Lumey. 2004. "Intrauterine famine exposure and body propotions at birth: the Dutch Hunger Winter." International Journal of Epidemiology 33: 831-836.

Susser Ezra, Lin SP. Schizophrenia after prenatal exposure to the Dutch Hunger Winter of 19441945. Arch Gen Psychiatry. 1992;49(12):983-988.

Susser, Ezra, Richard Neugebauer, Hans W Hoek, Alan S Brown, Shang Lin, Daniel Labovitz, and Jack M Gorman. 1996. "Schizophrenia after prenatal famine: further evidence." Archives of general psychiatry no. 53 (1):25.

Susser, Ezra, St Clair, D. 2013. Prenatal famine and adult mental illness: interpreting concordant and discordant results from the Dutch and Chinese Famines. Social science \& medicine (1982), 97, 325.

ter Braak, Edith W. M. T., Evers, Inge M., Erkelens, D. Willem, \& Visser, Gerard H. A. 2002. Maternal hypoglycemia during pregnancy in type 1 diabetes: maternal and fetal consequences. Diabetes/Metabolism Research and Reviews, 19, 96-105.

van Ewijk, Reyn. 2011. "Long-term health effects on the next generation of Ramadan fasting during pregnancy." Journal of health economics no. 30 (6):1246-1260. 
Table 1: Summary Statistics for Male Muslim Immigrants (excluding self-employed individuals) in Denmark

\begin{tabular}{|c|c|c|}
\hline Variable & Mean & Standard Deviation \\
\hline Employment (0/1) & 0.567 & $(0.495)$ \\
\hline Education (in months) & 138.30 & $(40.13)$ \\
\hline Hours of work (including zeros) & 992.94 & $(882.46)$ \\
\hline Hours of work $(>0)$ & 1431.61 & $(703.40)$ \\
\hline Salary income, $(>0)$ DKK & 250,469 & $(160,225)$ \\
\hline Hourly wage rate, DKK & 172.40 & $(86.63)$ \\
\hline Age & 40.788 & $(8.173)$ \\
\hline Born outside Denmark & 0.916 & $(0.278)$ \\
\hline Years since migration ( 0 if born in Denmark) & 15.629 & $(9.288)$ \\
\hline \multicolumn{3}{|l|}{ Month of Birth } \\
\hline 1 (January) & 0.083 & $(0.276)$ \\
\hline 2 (February) & 0.089 & $(0.285)$ \\
\hline 3 (March) & 0.105 & $(0.307)$ \\
\hline 4 (April) & 0.088 & $(0.283)$ \\
\hline 5 (May) & 0.090 & $0.286)$ \\
\hline 6 (June) & 0.082 & $(0.274)$ \\
\hline 7 (July) & 0.071 & $(0.256)$ \\
\hline 8 (August) & 0.079 & $(0.270)$ \\
\hline 9 (September) & 0.082 & $(0.275)$ \\
\hline 10 (October) & 0.082 & $(0.274)$ \\
\hline 11 (November) & 0.071 & $(0.257)$ \\
\hline 12 (December) & 0.078 & $(0.268)$ \\
\hline \multicolumn{3}{|l|}{ Country of Origin } \\
\hline Turkey & 0.296 & $(0.456)$ \\
\hline Pakistan & 0.104 & $(0.305)$ \\
\hline Iraq & 0.134 & $(0.340)$ \\
\hline Lebanon (Palestinians) & 0.111 & $(0.315)$ \\
\hline Iran & 0.119 & $(0.324)$ \\
\hline Somalia & 0.077 & $(0.267)$ \\
\hline Afghanistan & 0.052 & $(0.222)$ \\
\hline Other Muslim countries & 0.106 & $(0.308)$ \\
\hline \multicolumn{3}{|l|}{ Exposure to Ramadan in Utero } \\
\hline Definitely not exposed to Ramadan & 0.129 & $(0.336)$ \\
\hline Probably not exposed to Ramadan & 0.039 & $(0.193)$ \\
\hline $0^{\text {th }}$ Month & 0.083 & $(0.275)$ \\
\hline $1^{\text {st }}$ Month & 0.081 & $(0.273)$ \\
\hline $2^{\text {nd }}$ Month & 0.079 & $(0.269)$ \\
\hline $3^{\text {rd }}$ Month & 0.084 & $(0.277)$ \\
\hline $4^{\text {th }}$ Month & 0.080 & $(0.271)$ \\
\hline $5^{\text {th }}$ Month & 0.082 & $(0.274)$ \\
\hline $6^{\text {th }}$ Month & $\begin{array}{l}0.002 \\
0.079\end{array}$ & $(0.271)$ \\
\hline $7^{\text {th }}$ Month & 0.089 & $(0.284)$ \\
\hline $8^{\text {th }}$ Month & 0.089 & $(0.285)$ \\
\hline $9^{\text {th }}$ Month & 0.087 & $(0.281)$ \\
\hline \multicolumn{3}{|l|}{ Community of Residence } \\
\hline Copenhagen area $(0 / 1)$ & 0.479 & 0.500 \\
\hline Aarhus, Odense, Aalborg (0/1) & 0.185 & 0.389 \\
\hline All other areas $(0 / 1)$ & 0.336 & 0.472 \\
\hline Number of observations & \multicolumn{2}{|r|}{38,637} \\
\hline
\end{tabular}


Table 2: Determining the Month of Intrauterine Exposure to Ramadan

Days between date of birth and start date of the last

Month of gestation in which Ramadan began

Ramadan

$\begin{array}{cc}\text { 1-30 days } & 9 \\ \text { 31-59 days } & 8 \\ \text { 60-89 days } & 7 \\ 90-118 \text { days } & 6 \\ \text { 119-148 days } & 5 \\ \text { 149-177 days } & 4 \\ \text { 178-207 days } & 3 \\ 208-236 \text { days } & 2 \\ 237-266 \text { days } & 1 \\ 267-296 \text { days } & 0 \\ 297-310 \text { days } & \text { Probably not exposed to Ramadan } \\ 311-355 \text { days } & \text { Definitely not exposed to Ramadan }\end{array}$

Notes: We assume a normal human gestation period of 266 days. Following the algorithm used by Almond, Mazumder, van Ewijk (2011), we assign those individuals conceived within 14 days after Ramadan into the "Probably not exposed" category and those conceived later than 14 days after Ramadan into the "Definitely not exposed" category. A new month of Ramadan begins on the $356^{\text {th }}$ day after the start date of the last Ramadan. 
Table 3: Summary Statistics for Non-Muslim Immigrants (excluding self-employed individuals) in Denmark

\begin{tabular}{|c|c|c|}
\hline Variable & Means & Standard Deviation \\
\hline Employment (0/1) & 0.692 & $(0.462)$ \\
\hline Education (in months) & 153.82 & (35.38) \\
\hline Hours of work (including zeros) & 1159.76 & $(809.91)$ \\
\hline Hours of work $(>0)$ & 1442.87 & (638.43) \\
\hline Salary income, $(>0)$ DKK & 258,960 & $(173,106)$ \\
\hline Hourly wage rate, DKK & 182.07 & $(113.14)$ \\
\hline Age & 37.871 & $(8.4382)$ \\
\hline Born outside Denmark & 0.963 & $(0.190)$ \\
\hline Years since migration (0 if born in Denmark) & 9.319 & $(9.451)$ \\
\hline Month of Birth & & \\
\hline 1 (January) & 0.078 & $(0.268)$ \\
\hline 2 (February) & 0.079 & $(0.270)$ \\
\hline 3 (March) & 0.085 & $(0.279)$ \\
\hline 4 (April) & 0.085 & $(0.279)$ \\
\hline 5 (May) & 0.086 & $(0.280)$ \\
\hline 6 (June) & 0.082 & $(0.275)$ \\
\hline 7 (July) & 0.080 & $(0.271)$ \\
\hline 8 (August) & 0.084 & $(0.278)$ \\
\hline 9 (September) & 0.083 & $(0.276)$ \\
\hline 10 (October) & 0.086 & $(0.280)$ \\
\hline 11 (November) & 0.083 & $(0.277)$ \\
\hline 12 (December) & 0.088 & $(0.283)$ \\
\hline Country of Origin & & \\
\hline Poland & 0.252 & $(0.434)$ \\
\hline Vietnam & 0.084 & $(0.278)$ \\
\hline Thailand & 0.014 & $(0.117)$ \\
\hline Philippines & 0.020 & $(0.141)$ \\
\hline China & 0.059 & $(0.235)$ \\
\hline Sri Lanka & 0.066 & $(0.248)$ \\
\hline Other non-Muslim countries & 0.505 & $(0.500)$ \\
\hline Exposure to Ramadan in Utero & & \\
\hline Definitely not exposed to Ramadan & 0.120 & $(0.325)$ \\
\hline Probably not exposed to Ramadan & 0.037 & $(0.190)$ \\
\hline $0^{\text {th }}$ Month & 0.084 & $(0.278)$ \\
\hline $1^{\text {st }}$ Month & 0.081 & $(0.273)$ \\
\hline $2^{\text {nd }}$ Month & 0.081 & $(0.273)$ \\
\hline $3^{\text {rd }}$ Month & 0.088 & $(0.283)$ \\
\hline $4^{\text {th }}$ Month & 0.083 & $(0.276)$ \\
\hline $5^{\text {th }}$ Month & 0.087 & $(0.282)$ \\
\hline $6^{\text {th }}$ Month & 0.081 & $(0.277)$ \\
\hline $7^{\text {th }}$ Month & 0.085 & $(0.278)$ \\
\hline $8^{\text {th }}$ Month & 0.083 & $(0.276)$ \\
\hline $9^{\text {th }}$ Month & 0.086 & $(0.281)$ \\
\hline Community of Residence & & \\
\hline Copenhagen area $(0 / 1)$ & 0.346 & $(0.476)$ \\
\hline Aarhus, Odense, Aalborg (0/1) & 0.150 & $(0.357)$ \\
\hline All other areas (0/1) & 0.504 & $(0.500)$ \\
\hline Number of observations & \multicolumn{2}{|c|}{35,100} \\
\hline
\end{tabular}


Table 4: The Effect of Ramadan Exposure in Utero on Labor Market Performance - Sample of Muslim Males

\begin{tabular}{|c|c|c|c|c|}
\hline Ramadan Exposure & Employment & $\begin{array}{l}\text { Logarithm of Annual } \\
\text { Salary Income }\end{array}$ & $\begin{array}{l}\text { Logarithm of Hourly } \\
\text { Wage Rate }\end{array}$ & $\begin{array}{c}\text { Logarithm of Annual Hours of } \\
\text { Work }\end{array}$ \\
\hline \multirow[t]{2}{*}{ Probably not } & -0.007 & 0.019 & $-0.022 *$ & $0.055 * *$ \\
\hline & $(0.016)$ & $(0.030)$ & $(0.009)$ & $(0.027)$ \\
\hline \multirow[t]{2}{*}{$0^{\text {th }}$ Month } & -0.006 & -0.005 & $-0.014^{*}$ & 0.038 \\
\hline & $(0.009)$ & $(0.028)$ & $(0.008)$ & $(0.028)$ \\
\hline \multirow[t]{2}{*}{$1^{\text {st }}$ Month } & 0.000 & 0.031 & -0.001 & 0.033 \\
\hline & $(0.012)$ & $(0.028)$ & $(0.007)$ & $(0.024)$ \\
\hline \multirow[t]{2}{*}{$2^{\text {nd }}$ Month } & -0.002 & -0.003 & 0.004 & 0.001 \\
\hline & $(0.011)$ & $(0.028)$ & $(0.008)$ & $(0.027)$ \\
\hline \multirow[t]{2}{*}{$3^{\text {rd }}$ Month } & 0.001 & 0.033 & -0.002 & 0.031 \\
\hline & $(0.010)$ & $(0.034)$ & $(0.008)$ & $(0.029)$ \\
\hline \multirow[t]{2}{*}{$4^{\text {th }}$ Month } & 0.011 & 0.013 & 0.001 & 0.009 \\
\hline & $(0.011)$ & $(0.052)$ & $(0.008)$ & $(0.045)$ \\
\hline \multirow[t]{2}{*}{$5^{\text {th }}$ Month } & 0.013 & 0.041 & 0.005 & 0.031 \\
\hline & $(0.009)$ & $(0.027)$ & $(0.008)$ & $(0.034)$ \\
\hline \multirow[t]{2}{*}{$6^{\text {th }}$ Month } & 0.009 & 0.004 & -0.003 & -0.000 \\
\hline & $(0.008)$ & $(0.034)$ & $(0.008)$ & $(0.033)$ \\
\hline \multirow[t]{2}{*}{$7^{\text {th }}$ Month } & $-0.026 * *$ & $-0.053^{*}$ & -0.003 & $-0.047^{*}$ \\
\hline & $(0.012)$ & $(0.029)$ & $(0.008)$ & $(0.028)$ \\
\hline \multirow[t]{2}{*}{$8^{\text {th }}$ Month } & 0.009 & -0.018 & -0.004 & -0.023 \\
\hline & $(0.009)$ & $(0.031)$ & $(0.008)$ & $(0.026)$ \\
\hline \multirow[t]{2}{*}{$9^{\text {th }}$ Month } & 0.005 & 0.007 & 0.000 & -0.005 \\
\hline & $(0.010)$ & $(0.041)$ & $(0.007)$ & $(0.042)$ \\
\hline Number of observations & 38,627 & 26,763 & 26,608 & 26,799 \\
\hline
\end{tabular}

Notes: Robust standard errors clustered at the community are in parentheses. ${ }^{* *},{ }^{* *}$, and * indicate that the estimate is statistically significant at the 99th, 95th, and 90th percent level of confidence, respectively. The omitted category includes persons who are classified as "Certainly not exposed.” The following control variables are included in the estimations but not shown: age, country of origin, years since immigration, month of birth, and community of residence. 
Table 5: Difference-in-Difference Estimates of the Effect of Ramadan Exposure in Utero on Labor Market Performance

\begin{tabular}{|c|c|c|c|c|}
\hline $\begin{array}{l}\text { Ramadan } \\
\text { Exposure*Muslim }\end{array}$ & Employment & $\begin{array}{c}\text { Logarithm of Annual } \\
\text { Salary Income }\end{array}$ & $\begin{array}{c}\text { Logarithm of Hourly } \\
\text { Wage Rate }\end{array}$ & $\begin{array}{c}\text { Logarithm of Annual } \\
\text { Hours of Work }\end{array}$ \\
\hline \multirow[t]{2}{*}{ Probably not*Muslim } & -0.009 & 0.047 & -0.014 & $0.073^{*}$ \\
\hline & $(0.019)$ & $(0.038)$ & $(0.012)$ & $(0.037)$ \\
\hline \multirow[t]{2}{*}{$0^{\text {th }}$ Month*Muslim } & 0.009 & -0.012 & -0.017 & 0.007 \\
\hline & $(0.012)$ & $(0.035)$ & $(0.011)$ & $(0.032)$ \\
\hline \multirow[t]{2}{*}{$1^{\text {st }}$ Month*Muslim } & 0.003 & 0.039 & 0.008 & 0.014 \\
\hline & $(0.013)$ & $(0.035)$ & $(0.009)$ & $(0.032)$ \\
\hline \multirow[t]{2}{*}{$2^{\text {nd }}$ Month*Muslim } & -0.000 & -0.032 & 0.005 & -0.025 \\
\hline & $(0.013)$ & $(0.040)$ & $(0.012)$ & $(0.039)$ \\
\hline \multirow[t]{2}{*}{$3^{\text {rd }}$ Month*Muslim } & 0.014 & 0.001 & 0.011 & -0.015 \\
\hline & $(0.014)$ & $(0.039)$ & $(0.012)$ & $(0.035)$ \\
\hline \multirow[t]{2}{*}{$4^{\text {th }}$ Month*Muslim } & 0.006 & -0.021 & -0.006 & -0.015 \\
\hline & $(0.014)$ & $(0.059)$ & $(0.011)$ & $(0.051)$ \\
\hline \multirow{2}{*}{$5^{\text {th }}$ Month*Muslim } & 0.018 & -0.003 & 0.016 & -0.016 \\
\hline & $(0.011)$ & $(0.035)$ & $(0.011)$ & $(0.040)$ \\
\hline \multirow[t]{2}{*}{$6^{\text {th }}$ Month*Muslim } & 0.013 & 0.011 & -0.001 & 0.003 \\
\hline & $(0.012)$ & $(0.039)$ & $(0.011)$ & $(0.037)$ \\
\hline \multirow[t]{2}{*}{$7^{\text {th }}$ Month*Muslim } & -0.016 & $-0.082 * *$ & 0.007 & $-0.068 * *$ \\
\hline & $(0.014)$ & $(0.037)$ & $(0.013)$ & $(0.034)$ \\
\hline \multirow[t]{2}{*}{$8^{\text {th }}$ Month*Muslim } & -0.003 & -0.062 & -0.005 & $-0.072 * *$ \\
\hline & $(0.011)$ & $(0.038)$ & $(0.012)$ & $(0.035)$ \\
\hline \multirow[t]{2}{*}{$9^{\text {th }}$ Month*Muslim } & -0.011 & -0.013 & -0.009 & -0.017 \\
\hline & $(0.014)$ & $(0.047)$ & $(0.011)$ & $(0.044)$ \\
\hline Number of observations & 73,659 & 54,570 & 54,226 & 54,976 \\
\hline
\end{tabular}

